$25 \%$ of $\mathrm{PhD}$ psychologists use techniques that increase the risk of memory suggestion.

We have noted that there is a distinction between the claims of recovery of a memory of a single event and the claims of recovery of many memories of hundreds of events extending over long periods of many years. The reports that have been received by the False Memory Syndrome Foundation generally include claims that a person has recovered many memories of numerous events that took place over many years after total amnesia for all these events. Such claims represent a new kind of phenomenon. In 1989 Briere introduced a new mental mechanism that he said was only recently discovered and causes patients to become completely amnestic and suffer the "complete loss of childhood sexual abuse memories" (p. 49). Extraordinary claims deserve extraordinary evidence. Without such evidence, such claims must be taken with scepticism.

The position of the Foundation has always been that whether they are continuous or recovered, some memories are true, some a mixture of fact and fantasy and some are false. The problem is to know the difference.

BrIERE, J. (1989) Therapy for Adults Molested as Children: Beyond Survival. New York: Springer.

BREWIN, C. R. Scientific status of recovered memories. British Journal of Psychiatry, 169, 131-134.

Poole, D., et al (1994) Psychotherapy and the recovery of memories of childhood sexual abuse: US and British practitioners' opinions, practices, and experience. Journal of Consulting and Clinical Psychology, 63, 426-437.

FMS Foundation

P. FREYD,

Phildelphia, PA 19104

USA

Baclofen therapy for rigidity associated with Lewy body dementia

SIR: Lewy body dementia (LBD) often shows a marked sensitivity to neuroleptics (McKeith et al, 1992). Anticholinergic agents used to treat extrapyramidal side-effects of these drugs are often unsuccessful in LBD and can exacerbate confusion and psychosis. We report a case of LBD with severe extrapyramidal rigidity who responded well to treatment with baclofen, a $\gamma$-aminobutyric acid agonist.

Mrs T., a 90-year-old widow, was admitted with a two-year history of memory loss. Distressing visual hallucinations included "a baby monkey with a long tail". She had become disoriented and repeatedly and inappropriately telephoned her neighbours. Cognition was globally impaired (Mini Mental State Examination 13/30). Physical examination revealed only impaired visual acuity. Investigations were normal. Sulpiride (100 $\mathrm{mg}$ per day) was commenced but the patient soon became drowsy and showed marked stiffness and cogwheeling. She became immobile, uncommunicative and doubly incontinent. The sulpiride was stopped and a diagnosis of "probable dementia with Lewy bodies" was made (International Workshop on Dementia with Lewy Bodies, 1996, in press). Procyclidine was commenced and gradually increased to $10 \mathrm{mg}$ t.d.s. but rigidity steadily worsened. The patient was frightened, screaming at times, hardly ate and required intermittent intravenous hydration. Eleven weeks after stopping the sulpiride, baclofen was started and cautiously increased to $15 \mathrm{mg}$ t.d.s. while procyclidine was reduced and stopped. (Baclofen may itself exacerbate psychosis and confusion.)

Two weeks later Mrs T. was much more settled, with no signs of distress. Her affect was reactive, while verbal communication and oral input improved markedly. Stiffness gradually resolved and mobility improved. In another patient with LBD we have again found that baclofen was far more effective than procyclidine in reducing stiffness. Baclofen may therefore be useful in the treatment of rigidity associated with diffuse Lewy body dementia, and merits further evaluation. (Acknowledgement: Thanks to Rodney Walker for his advice.)

INTERNATIONAL WORKSHOP ON DEMENTIA WITH LEWY BODIES (1996) Consensus criteria for the clinical diagnosis of dementia with Lewy bodies. Neurology, in press.

McKeith, I. G., FaIrbairn, A., Perry, R., el al (1992) Neuroleptic sensitivity in patients with senile dementia of Lewy body type. British Medical Journal, 305, 673-678.

Department of Psychiatry

M. Moutoussis

Princes Alexandra Hospital

Harlow CM20 1QX

University College London Medical School

Middlesex Hospital

London WIN 8AA

\section{An atypical case of parasuicide or 'bradysuicide'}

SIR: The term parasuicide refers to a non-fatal deliberate act of self-injury or ingestion of substances in excess of normally used doses.

A 35-year-old kindergarten teacher, who had a past history of sedative overdose, became depressed upon her father's death and decided to end her life 